\title{
Transgenic mouse models in the study of reproduction: insights into GATA protein function
}

\author{
Sergei G Tevosian \\ Department of Physiological Sciences, College of Veterinary Medicine, University of Florida, \\ Gainesville, Florida 32610, USA \\ Correspondence should be addressed to S G Tevosian; Email: stevosian@ufl.edu
}

\begin{abstract}
For the past 2 decades, transgenic technology in mice has allowed for an unprecedented insight into the transcriptional control of reproductive development and function. The key factor among the mouse genetic tools that made this rapid advance possible is a conditional transgenic approach, a particularly versatile method of creating gene deletions and substitutions in the mouse genome. A centerpiece of this strategy is an enzyme, Cre recombinase, which is expressed from defined DNA regulatory elements that are active in the tissue of choice. The regulatory DNA element (either genetically engineered or natural) assures Cre expression only in predetermined cell types, leading to the guided deletion of genetically modified (flanked by loxP or 'floxed' by loxP) gene loci. This review summarizes and compares the studies in which genes encoding GATA family transcription factors were targeted either globally or by Cre recombinases active in the somatic cells of ovaries and testes. The conditional gene loss experiments require detailed knowledge of the spatial and temporal expression of Cre activity, and the challenges in interpreting the outcomes are highlighted. These studies also expose the complexity of GATA-dependent regulation of gonadal gene expression and suggest that gene function is highly context dependent. Reproduction (2014) 148 R1-R14
\end{abstract}

\section{Introduction}

\section{Transgenic technologies in mice}

Global (germline) targeting technology

What we observe is not nature itself, but nature exposed to our method of questioning

Werner Heisenberg

The introduction of the first transgenic mouse lines 30 years ago opened the new chapter in biomedical science (Costantini \& Lacy 1981, Wagner et al. 1981). Soon thereafter, the isolation of mouse pluripotent embryonic stem cells (ESCs) coupled with the technique of targeted (homologous) DNA recombination formed the foundation for carrying out gene deletion or modification in mouse genome (Thomas et al. 1986, Thomas \& Capecchi 1987). These two closely related transgenic technologies revolutionized biomedical and biotechnological enterprises and quickly established genetically engineered mice as an unrivaled model system for understanding human development and disease. Today, mice remain the most widely used model organism in health sciences due to their genetic and physiological similarities to humans, fairly low maintenance costs, a remarkably short reproductive period, and robust fecundity. The importance of the mouse as a biomedical species of choice is reflected in the fact that its fullgenome sequence became available shortly after that of a human (Lander et al. 2001, Waterston et al. 2002).

Global, or germline, gene targeting describes a process in which genetic modifications (including complete or partial promoter or gene deletions or gene mutations) are introduced into a specific locus through the use of homologous recombination in ESCs. The targeting DNA cassette is delivered to ESCs by electroporation and the recombinant clones are selected by their drug resistance. One copy of the WT gene can be replaced with the targeting construct by homologous recombination. Once the ESC clone containing the desired recombination event is identified, the modified ESCs are injected into the blastocysts that are transferred into foster mothers. The offspring born from the foster animals is comprised of cells that originated from two genetically unrelated strains (blastocyst and ESCs) and is termed chimeric founder animals. If a chimeric animal possesses germ cells derived from the ESC clone, the genetic alteration will be propagated to the offspring, generating heterozygous mutant mice. Animals that are heterozygous for the desired mutation are interbred. This method is widely used for the generation of a null allele (a knockout) or a modified allele (a knock-in). 
Despite many technical advances, the ESC-based knockout technology in mice remains far from trivial and requires highly trained professionals to avoid numerous hurdles along the way. Over the years, many laboratories attempted to simplify the targeting process, make it more versatile and applicable to species other than mice. While the detailed survey of these technologies is outside of the review's scope, several new developments in genome editing are noteworthy. The TALEN (transcription-activator-like effector nuclease) approach employs a fusion protein comprising nonspecific double-strand break-inducing nuclease domain of Fokl restriction enzyme and a TALE, a modular sequence-specific DNA-binding protein. TALE repeat domains could be designed and assembled for recognizing any desired DNA sequence following a simple 'onedomain-to-one-nucleotide' code (reviewed in Pennisi (2012)). Recently TALEN technology has been successfully used for overcoming a long-standing problem of targeting Y chromosome in mice (Wang et al. 2013).

Another genome-editing strategy based on the bacterial CRISPR (clustered, regularly interspaced, short palindromic repeat)-associated protein 9 nuclease from Streptococcus pyogenes (Cas9) holds even more promise. Cas9 is an RNA-guided nuclease that uses conventional base-pairing rules to deliver its nuclease moiety to a target DNA sequence with a swappable genetically engineered RNA. CRISPR-Cas9 system eliminates the need for ESC step altogether, allows targeting several genes at once, and is applicable to a wide variety of species (for recent reviews, see Mali et al. (2013) and Sander \& Joung (2014)).

\section{Transgenic Cre/Lox technology}

Similar to global gene targeting, conditional gene targeting also produces gene deletions or mutations, but these modifications are intended to be limited in a temporal and spatial manner. The so-called 'Cre/Lox' targeting technology is modeled after a bacteriophage P1 recombination system and is currently the most commonly used approach for gene modification in mice. This strategy, which also employs ESC, is initiated by incorporating two strategically positioned 34-bp DNA sequences (LoxP sites) into the targeted locus. The P1 Cre recombinase specifically recognizes a pair of LoxP sites in the whole genome and performs DNA strand exchange between them. This process results in the excision of the intervening sequence. In a targeting DNA construct, the two LoxP sites are usually inserted in the nonessential intron sequences flanking exonic DNA coding for a critical portion of the protein. This arrangement allows the gene that is flanked by LoxP sites ('floxed') to retain its WT activity until Cre recombination removes or replaces the essential coding element, leading to gene inactivation or modification respectively.
For the experiment, a mouse line derived from ESCs that contain the floxed gene of interest (Floxed strain) is crossed with another strain that expresses the Cre recombinase (Cre strain) in a specific tissue or cell type. Recombination and inactivation of the target gene are restricted to cells that activate the expression of Cre recombinase; in all other cells and tissues, the floxed gene retains both of the LoxP sequences and remains active. A critical improvement in the versatility of the Cre/Lox system came with the introduction of inducible Cre lines. Inducible Cre mouse strains express a modified, latent form of Cre recombinase that can be activated by an inducing agent (e.g. tamoxifen) administered at a desired time point in embryonic development or in adult life (see Jensen \& Dymecki (2014) for a recent review).

A critical element of a typical Cre/Lox experiment is the characterization of Cre recombinase activity. This experiment is normally carried out by crossing a Crestrain animal with a mouse of the opposite sex, harboring a transgenic cassette that includes the reporter gene controlled by the ubiquitously expressed promoter (Reporter strain). The floxed interrupter 'stop' sequence separates the reporter gene from its regulatory element and prevents the synthesis of the gene product in the Reporter strain. When these animals are crossed, the progeny that inherits both Cre gene and the reporter is used to assess Cre activity. The Cre-mediated excision of the interrupter sequence then brings the regulatory sequence in close proximity to the reporter gene and activates its expression. The promoter element used in these experiments is usually that of the ubiquitously expressed ROSA locus (Zambrowicz et al. 1997). Reporter genes normally encode proteins that can be detected without relying on a specific antibody, and the ones most commonly used are fluorescent proteins (enhanced green fluorescent protein (EGFP) or RFP), $\beta$-galactosidase ( $\beta$-gal), or alkaline phosphatase. Importantly, not only cells expressing Cre recombinase but also their direct progeny will stain positive for the reporter protein. As activation of a reporter gene permanently labels the progenitor cell where Cre recombination occurred, that expression is retained in all of the cell's descendants even in the absence of concomitant Cre activity. This experiment is a centerpiece of the lineage tracing (fate mapping) studies.

\section{Transgenic technology in the analysis of GATA protein in gonadal function}

\section{Expression of Gata genes in mice}

Transcription factors of the GATA family possess a signature double zinc finger DNA-binding domain that recognizes the GATA motif (WGATAR) found in the regulatory regions of numerous genes (reviewed in Molkentin (2000), Cantor \& Orkin (2005), Zaytouni et al. (2011) and Chlon \& Crispino (2012)). Six GATA 
proteins present in vertebrates are customarily divided into two groups of three, based on the expression pattern. GATA $1-3$ are most prominent in hematopoietic cell differentiation; in addition, they perform important functions in several other tissues (e.g. endothelial cells and neurons). GATA4- 6 are widely expressed outside of the hematopoietic system, including the gonads, heart, liver, lung, pancreas, and gut (reviewed in Patient \& McGhee (2002), LaVoie (2003) and Viger et al. (2008); see also Carrasco et al. (2012) and Xuan et al. (2012)). GATA proteins cooperate with other transcription factors to form a regulatory network that also includes nonDNA-binding interacting partners as well as other proteins with various enzymatic activities. It is hypothesized that GATA proteins serve to amplify (rather than specify) the expression of lineage-restricted genes, but the definitive proof of this hypothesis is still lacking.

\section{Expression of Gata genes in reproductive organs}

Gata4 appears to be the only GATA family member active in the development of bipotential gonad before sexual determination in mice. At embryonic day (E) E10.5-E11.5, Gata4 is already expressed in the somatic cells of the developing genital ridges (Defalco et al. 2011, Buganim et al. 2012, Hu et al. 2013). At E13.5, Gata4 expression becomes sexually dimorphic; in the testis, expression is notably upregulated in Sertoli cells and reduced to some extent in interstitial cells, whereas strong-to-moderate GATA4 expression is observed in the majority of ovarian somatic cells (Heikinheimo et al. 1997, Viger et al. 1998, Anttonen et al. 2003, Manuylov et al. 2008, Efimenko et al. 2013). A similar pattern of Gata4 expression has been reported in rats (Lavoie et al. 2004). In the postnatal ovaries, GATA4 is abundantly expressed in the granulosa cells of primary, preantral, and antral follicles as well as in endocrine theca cells, but not in primordial follicles or luteal cells (Viger et al. 2008). The other GATA protein, GATA6, closely follows GATA4 early in the ovarian development, with continuous expression in granulosa cells and theca cells of large follicles. In contrast to GATA4, GATA6 is present in oocytes and luteal cells (Heikinheimo et al. 1997, Viger et al. 1998). Gata2 expression in the murine embryonic ovary has also been described and is restricted to the germline from E11.5 to E15.5 (Siggers et al. 2002, Bhardwaj et al. 2008); however, the functional significance of this expression remains unknown.

In the testes, Gata4 expression persists in the somatic cells throughout life, with both Sertoli and Leydig cells expressing the protein (Viger et al. 1998, Anttonen et al. 2003, Imai et al. 2004). Similar to the ovary, GATA6 is another protein present in the somatic cells of the testis, and its expression was reported to commence at E14.5 in Sertoli cells (Robert et al. 2002). The expression of GATA6 in fetal Leydig cells has not been analyzed in detail; the data from our laboratory show that at
E15.5 GATA6 expression in fetal Leydig cells appears higher than that in Sertoli cells, while adult Leydig and Sertoli cells express the protein at a comparable level (SG Tevosian, unpublished observations).

In addition to GATA4 and GATA6, postnatal Sertoli cells express a third GATA protein, GATA1 (Yomogida et al. 1994). GATA1 expression is first observed in Sertoli cells in postnatal day 7 (PND 7) mice, and GATA1 is evenly expressed in all seminiferous tubules until 3 weeks of age. Shortly after, solitary Sertoli cells lacking GATA1 start to appear in some seminiferous tubules; in the adult testis, GATA1 expression is restricted to seminiferous tubules at stages VII, VIII, and IX of the seminiferous epithelial cycle (Yomogida et al. 1994). This expression pattern suggests that Gata1 expression in Sertoli cells is suppressed during embryonic development and by a signal originating from germ cells in the adult. Sertoli cell expression of GATA1 is noteworthy as this is the only place outside of the hematopoietic system where this protein is found. Despite the intriguing expression pattern, experiments aimed at determining the role of GATA1 in the testis suggest that GATA1 is not essential for Sertoli cell function (Fujiwara et al. 1996, Lindeboom et al. 2003). The expression of GATA3 or GATA5 has not been reported for mammalian gonads.

\section{GATA protein function in the cells of the reproductive system}

Before transgenic techniques became widely available in mice, the established approach for understanding gene function was overexpression studies in cultured cells. Here again, most studies focused on the role of the GATA4 protein and revealed several prospective targets of GATA4 regulation in the testis. Specifically, these studies suggested that GATA4 participates in the regulation of anti-Müllerian hormone (Amh; Viger et al. 1998, Tremblay \& Viger 1999, Watanabe et al. 2000), steroidogenic factor 1 /nuclear receptor subfamily 5, group A, member 1 (Sf1/Nr5a1; Tremblay \& Viger 2001), aromatase (Cyp19a1; Tremblay \& Viger 2001), inhibin alpha (Inha; Ketola et al. 1999), Star (Silverman et al. 2006, Nishida et al. 2008), and Rhox5 (Bhardwaj et al. 2008; see Viger et al. (2008) and Lavoie \& King (2009) for review). In granulosa cells, GATA4 was implicated to regulate a partially overlapping gene set: Cyp11a1 (Sher et al. 2007), Star (Silverman et al. 1999, 2006), Cyp19a1 (Cai et al. 2007, Stocco et al. 2007), and Inha (Anttonen et al. 2006). Similarly, Inha (Ketola et al. 1999, Feng et al. 2000), Star (Martin et al. 2012), and luteinizing hormone receptor (Lhcgr, Rahman et al. 2004) were identified as genes that are dependent on GATA4 in immortalized Leydig cells. While these studies illuminated a wide range of gonad-expressed genes as likely GATA4 targets, definitive conclusions regarding their temporal and spatial regulation in gonadal cells by GATA proteins could only emerge as a result of gene manipulation in vivo in mice. 


\section{GATA protein function revealed by global gene deletions}

An analysis of the function of GATA genes in reproduction through a global knockout has not been possible due to the embryonic lethality of Gata ${ }^{-/-}(\sim$ E8.0) and Gata6 ${ }^{-/-}(\sim$ E5.5) mice several days before the gonads arise (Kuo et al. 1997, Molkentin et al. 1997, Koutsourakis et al. 1999). However, a knock-in mutation was quite informative in defining the role of GATA4 in gonadal development. The function of GATA proteins is modified by binding to multi-type zinc finger cofactors of the FOG (Friend of GATA) family of transcription factors (for reviews, see Cantor \& Orkin (2005), Zaytouni et al. (2011) and Chlon \& Crispino (2012)). Two of these proteins are found in mammals: FOG1 and FOG2. FOG2 is co-expressed with GATA4 in the somatic cells of the gonads between E11.0 and E13.5; after E13.5, Fog2 gonadal expression is notably reduced and remains low during subsequent embryonic development ((Lu et al. 1999, Svensson et al. 1999, Tevosian et al. 1999, Anttonen et al. 2003, Manuylov et al. 2007a); SG Tevosian, unpublished observations).

The interaction between the two protein partners GATA4 and FOG2 allowed for exploring the role of GATA4 in gonadal development in vivo. A Gata4 knockin allele (Gata4 ${ }^{k i}$, a V217G amino acid substitution) generates a mutant form of the GATA4 that is incapable of interacting with FOG proteins (Crispino et al. 2001). Homozygous Gata4 ${ }^{k i / k i}$ embryos survive till E13.0 and die from cardiac malformations similar to those described in Fog2 $2^{-/-}$embryos (Tevosian et al. 2000, Crispino et al. 2001). An analysis of gonadal development in these animals demonstrated that both GATA4 and FOG2 partner proteins, as well as the physical interaction between them, are essential for male sex determination and testis differentiation (Tevosian et al. 2002). Fog $2^{-1-}$ and Gata $4^{k i / k i}$ mutant XY gonads express lower levels of the master regulator Sry (Gubbay et al. 1990) compared with the controls, and the expression of genes crucial for normal Sertoli (Sox9, Amh and Desert hedgehog (Dhh)) and Leydig (Cyp11a1, $3 \beta$ Hsd, and Cyp17a1) cell development is absent (Tevosian et al. 2002).

Similarly, ovarian gene expression program is profoundly disrupted upon loss of the GATA4-FOG2 interaction (Manuylov et al. 2008). The majority of ovarian genes essential for granulosa cell function is no longer expressed in the Gata4 ${ }^{k i / k i}$ and Fog2 $2^{-/-}$XX gonads. Specifically, both Fox/2 and the canonical Wnt/ $\beta$-catenin pathway, two critical pieces of the ovarian developmental program, are silenced in the absence of the GATA4-FOG2 interaction. Moreover, the Dkk1 gene, which encodes a secreted inhibitor of canonical $\beta$-catenin signaling, is strongly (approximately tenfold) activated in these mutants as early as E11.5 (Manuylov et al. 2008).
GATA protein function revealed by conditional gene targeting

A gene expression analysis in mice with a global loss of the GATA4-FOG2 interaction revealed that GATA4 and its transcription partner, FOG2, are indispensable for initiating embryonic development of both the testis and ovary. However, the Gata $4^{k i}$ mutation is not synonymous with a Gata4 loss of function, as the mutant GATA4 protein is impaired only in its ability to interact with the cofactor FOG proteins (Crispino et al. 1999). Moreover, the analysis of GATA4 gonadal function is restricted at the earliest stages of gonadogenesis. This limitation is normally attributed to the mid-gestational embryonic lethality of the GATA4/FOG2 mutants that prevents further examination. However, another reason is just as important; in the absence of the proteins, gonadal development becomes unhinged at the sex determination step. For example, deletion of a FOG2 gene (or Gata ${ }^{k i}$ mutation) leads to the downregulation of Sry expression, which alone could account for the subsequent demise of the testis gene expression program (Tevosian et al. 2002). Other experimental approaches were clearly needed to understand GATA gene function beyond the sex determination stage.

The first in vivo evidence that the GATA4-FOG2 partnership has gonadal regulatory targets other than Sry came from the analysis of dominant XX sex reversed transgenic mouse models. The serendipitous insertion of the tyrosinase transgene upstream of Sox9 in Odd sex animals (ocular degeneration with sex reversal, Ods) leads to the elevated expression of Sox9 in XX mice (Bishop et al. 1999). Similarly, in Wt1-Sox9 mice, Sox9 is overexpressed in gonads from the Wt1 regulatory elements within a yeast artificial chromosome (Vidal et al. 2001). In both lines, ectopic Sox9 initiates testis differentiation and a dominant, female-to-male, sex reversal is observed. This sex reversal is completely suppressed in Fog2 heterozygous animals and XX Fog $2^{+/-} ;$Wt1-Sox9 or Fog $2^{+/-}$; Ods mice develop into fertile females. The suppression of sex reversal in Fog2 heterozygous females results from an $\sim 50 \%$ downregulation of the Sox 9 transgenic expression. Importantly, neither of two transgenes is capable of initiating Sox9 expression in Fog2 null or Gata4 ${ }^{k i k i}$ embryos. These results suggested that female-to-male sex reversal observed in the transgenic $\mathrm{XX}$ gonads required an intact GATA4-FOG2 complex and relied on gene targets other than the Y chromosome-linked Sry gene that is absent in genetically female (XX) animals (Manuylov et al. 2007a). Similar conclusions were derived through the analysis of heterozygous Gata4 and Fog2 animals (Bouma et al. 2007).

Importantly, Cre/Lox recombination technology could be used successfully to identify multiple developmental requirements for a given protein for which the later roles are concealed by its early loss in a global knockout. 
To show the requirement of GATA proteins in sexual development after birth, several groups of investigators generated loss-of-function mutations in gonads using various Cre recombinase strains. To reveal the nature of GATA regulatory targets, Cre-mediated Gata4 gene deletion was carried out in the somatic cells of the testis. This approach circumvented the early embryonic lethality of global Gata knockouts and permitted the analysis of gonadal development that resulted from temporally and spatially restricted GATA inactivation.

\section{GATA proteins in testis development}

Sf1 (bacterial artificial chromosome (BAC)) Cremediated gene deletion demonstrates Gata4 function in testis development beyond sex determination. A Cre line of mice based on a BAC containing the Sf1 (Nr5a1) locus has been described (Bingham et al. 2006). This Sf1Cre is robustly expressed in places where the Sf1/ $\mathrm{Nr} 5 a 1$ gene is active, and the expression initiates before sex determination in the somatic cells of the developing gonads. Sf1Cre has been used successfully by several investigators to target genes expressed in gonads and adrenal gland (Kim et al. 2007a, 2008, Huang \& Yao 2010). In the testis, a Sf1Cre-mediated Gata4 flox/flox conditional deletion (designated as Sf1Cre; Gata4cKO) leads to the loss of GATA4 by E12.5 (Manuylov et al. 2011). These animals reveal a committed function of GATA4 in forming discrete testis cords and helped to identify genes that rely upon GATA4 regulation starting at E12.5.

Microarray analysis comparing control and mutant testis identified numerous gene expression changes upon Sf1Cre-mediated GATA4 loss. Interestingly, the gene that provided the most intriguing clues to GATA4 role in testis transcriptional regulation, Dmrt1, did not emerge through the microarray analysis, but was instead identified in a candidate gene approach. Expression and function of Dmrt1 gene have been extensively studied in multiple species (Matsuda et al. 2002, Smith et al. 2009, Yoshimoto et al. 2010). Remarkably, DMRT1's penchant for sex regulation is conserved not only among vertebrates, but also in Drosophila and nematodes (Raymond et al. 1998). This is quite unusual given that sex-determining mechanisms have little in common across phyla and even between vertebrates. In mammals Dmrt1 is highly specific to embryonic gonads where it is expressed in the developing Sertoli cells as well as in germ cells of both sexes. In the adult animals Dmrt1 expression becomes confined to the postnatal testis. Reports of disorders of sexual development in human patients strongly suggest that DMRT1 is important for male sex determination and embryonic testis differentiation (Raymond et al. 1999). Surprisingly, knockout of Dmrt1 in mice (Raymond et al. 2000) did not reveal the requirement for this gene during embryogenesis and prenatal testis differentiation of Dmrt1 ${ }^{-1-}$ mutants is unremarkable. Cre/Lox approach was instrumental in establishing the functions for Dmrt1 separately in the testis somatic and germ cell compartments. Postnatal differentiation of Sertoli cells is impaired upon Sertoli cell-specific DMRT1 loss, while centrifugal migration of developing germ cells to the tubular periphery and gonocyte mitotic reactivation and viability require germ cell DMRT1 expression (Kim et al. 2007b). Recent research has highlighted a role for Dmrt1 in maintaining the fidelity of testis sex determination (Matson et al. 2011).

Manuylov et al. (2011) have shown that DMRT1 protein expression is lost from the Sertoli cells of Sf1Cre; Gata4cKO embryonic testis (Manuylov et al. 2011). The expansion of Sertoli cells in these mutants to completely fill the developing testis cords (Manuylov et al. 2011) strongly resembles the phenotype in postnatal Dmrt $1^{-/-}$ mutants (Raymond et al. 2000). Importantly, the testis cord defect in the Sf1Cre; Gata4cKO animals is manifested embryonically, considerably earlier than that in Dmrt $1^{-}$animals at PND 14. The most parsimonious explanation for this outcome is the deregulation of the expression of other genes in the absence of GATA4. Microarray analysis identified multiple genes that are strongly downregulated as a result of GATA4 loss. The expression of two such genes, cystatin 9 (Cst9) and clusterin (Clu/Apo)), is easily detectable by in situ hybridization in the control testis but no longer observed in the E14.5 Sf1Cre; Gata4cKO organ. No testis abnormalities have been reported in mouse mutants deficient for either gene (Bailey et al. 2002, Tohonen et al. 2005, Hasegawa et al. 2006), however their combined loss could be a contributing factor in the Sf1Cre; Gata4cKO phenotype. Moreover, a role for Clu/ApoJ in augmenting cell death in the testis has been proposed (Kaisman-Elbaz et al. 2009), and the downregulation of Clu/ApoJ upon GATA4 absence may allow Sertoli cells to evade apoptosis.

In summary, the range of genes controlled by GATA factors in the somatic cells is highly dynamic (see also below), however these results provide in vivo evidence for GATA4 requirement in Sertoli cell Dmrt1 expression and in organizing the development of testis cords. Importantly, the loss of Dmrt1 expression is not merely a part of the overall failure of Sertoli cell differentiation in the absence of GATA4, as the majority of Sertoli-specific genes are expressed normally. Furthermore, the requirement for GATA4 in maintaining Dmrt1 expression is not absolute, and other GATA proteins are likely competent to perform this task. Specifically, while GATA4 is obligatory for DMRT1 expression in embryonic Sertoli cells where it is a sole GATA factor, the DMRT1 protein reappears in the Sf1Cre; Gata4cKO postnatal testis where GATA6 and GATA1 remain strongly expressed. Similarly, after the acute loss of Gata4 in the inducible Wt1CreERT2; Gata4cKO adult mice (see below), the somatic expression of Dmrt1 remains unchanged (Manuylov et al. 2011). 
The upstream regulatory DNA elements guiding Sertoli cell Dmrt1 expression were examined in primary cultures of rat Sertoli cells (Lei \& Heckert 2004, Lei et al. 2009). It was reported that the minimal region necessary for Sertoli cell-specific transcriptional activity is located between -3.2 and $-2.8 \mathrm{~kb}$ upstream of the transcriptional start site and contains several regulatory elements capable of binding GATA4. Whether the same enhancer element is engaged by GATA4 in species other than rat remains to be established.

Sf1Cre; Gata4cKO male mice exhibit neither the early arrest of testis differentiation that is characteristic of the GATA4 ${ }^{\mathrm{ki}}$ phenotype (Tevosian et al. 2002) nor sex reversal. Although their testes eventually succumb to a developmental block and undergo germ cell attrition, gonadal differentiation in these mutants appears to initiate normally (Manuylov et al. 2011). This phenotype occurs despite the fact that Sf1Cre; Gata4CKO animals lose GATA4 protein expression, while GATA4 ${ }^{\mathrm{ki}}$ gonads express the full-length protein that retains most of its function. The likely explanation for an improved outcome is the timing of the Gata4 gene deletion that follows rather than precedes sex determination in Sf1Cre-conditional animals. At E11.5, many GATA4positive cells remained detectable in the Sf1Cre; Gata4cKO gonads (Manuylov et al. 2011). These residual GATA4-positive cells are present within a critical window of time (E11.0-E11.25) during which SRY is competent to activate the Sertoli cell pathway in a sufficient number of precursor cells ((Bullejos \& Koopman 2005, Hiramatsu et al. 2009); see Kashimada \& Koopman (2010) for review). This timing of excision hypothesis was further explored using an inducible Wt1CreERT2 as described below.

Dynamic phenotypes of Gata4 loss during gonadal development. To evaluate the hypothesis that the timing of Gata4 gene deletion relative to the window of sex determination is critical, Manuylov et al. (2011) used tamoxifen-inducible CreERT2 expressed from the endogenous Wt1 locus (Wt1CreERT2) (Zhou et al. 2008). Pregnant females carrying litters containing mutant fetuses (Wt1CreERT2; Gata $4^{\text {flox/flox }}$, further Wt1CreERT2; Gata4cKO) were injected with tamoxifen to activate Cre function, and the fetuses were harvested several days later. Upon injection with tamoxifen at E10.5, Wt1-driven CreERT2 was active in somatic progenitor cells, recapitulating endogenous Wt1 gonadal expression. Unlike Sf1Cre; Gata4cKO embryos, E15.5 XY embryos that underwent E10.5 Wt1CreERT2mediated deletion of floxed Gata4 (Wt1CreERT2; 10.5_Gata4cKO) exhibited a comprehensive block of testicular differentiation and male-to-female sex reversal. Specifically, expression of male-specific genes (e.g. Sertoli marker SOX9 or Leydig 3BHSD) in the XY Wt1CreERT2_10.5_Gata4cKO embryos was either strongly diminished or not observed. Instead, the gonadal cells in the mutants initiated the expression of the early ovary-specific marker FOXL2. In summary, compared to the Sf1Cre; Gata4cKO mutants that develop atypical, but unambiguous testes, male pathway of differentiation in Wt1CreERT2_10.5_Gata4cKO gonads was profoundly disturbed by the absence of the GATA4 protein (Manuylov et al. 2011). In contrast, the activation of Wt1CreERT2 just 1 day later at E11.5 (Wt1CreERT2; 11.5_Gata4CKO) led to a phenotype very similar to that of Sf1Cre; Gata4CKO animals. This result suggests that both Sf1Cre; Gata4cKO and Wt1CreERT2; 11.5_Gata4CKO males do not experience sex reversal, as sufficient numbers of GATA4-positive cells persist to support male sex determination during the window of opportunity.

These results establish the requirement for the GATA4FOG2 complex in somatic sex specification. In developing gonads, supporting cell progenitors depend on the transcriptional regulatory network that includes GATA4 and FOG2 to successfully transition from their undifferentiated bipotential state to acquire a male or female sex-specific identity (Tevosian et al. 2002, Buganim et al. 2012). This is corroborated by the fact that gonads in Gata4 ${ }^{k i / k i}$ or Fog2 ${ }^{-/-}$mutants no longer express malespecific (Sox9, Dhh, Amh, or somatic Dmrt1; Tevosian et al. 2002, Manuylov et al. 2011) or female-specific (Foxl2, Fst, or Sprr2d; Manuylov et al. 2008) genes. In contrast, conditional gene deletion is fully complete only past the point of sex determination. After somatic cells commit sex determination, the majority of Sertoli-specific genes no longer require GATA4 for their continuous expression. Hence, the range of GATA4 duties in differentiated Sertoli cells appears to focus on regulating a subset of its former targets (e.g. Dmrt1). The limited set that remains under GATA4 control includes genes required for Sertoli cell maturation, testis cord organization and germ cell viability.

Recently, Hu et al. (2013) demonstrated an even earlier requirement for GATA4 in the developing reproductive system. A tamoxifen-inducible Cre/Lox system where the ubiquitously expressed synthetic chicken $\beta$-actin (CAG) promoter drives CreER expression was used to conditionally delete Gata4 in mouse embryos after E8.75. This approach allowed conditional mutant embryos to survive to $\sim$ E11.5. Embryos deficient for Gata4 at this developmental time point show neither coelomic epithelial thickening nor expression of the early gonadal differentiation factors LHX9 and NR5A1. This study indicates that Gata4 is required for the formation of the genital ridge in mice prior to its role in gonadal sex determination.

Thus far, no Cre/Lox approach had been described that inactivated Gata4 to produce a phenotype similar to that of a Fog2 deletion or Gata ${ }^{4 k i}$ mutation with a sex determination block, early demise of both sex differentiation programs, and a characteristic change in gene expression pattern. For example, the tenfold increase in $D k k 1$ gene expression observed in Gata ${ }^{4 k i / k i}$ gonads at 
E11.5 (Manuylov et al. 2008) has not been recapitulated in any conditional setting. Most likely, this result is due to a technical difficulty of generating a suitable Cre carrier line capable of deleting genes just in time to block sex determination in a newly developed genital ridge ( $\mathrm{Hu}$ et al. 2013). An attempt to delete Gata4 using Wt1CreERT2 with induction a day earlier, at E9.5, led either to a sex reversal (as described above for the E10.5 induction) or to embryonic lethality (most likely due to the loss of Gata4 function in the pericardium) (Zhou et al. 2008). It is formally possible that, under condition of GATA4 loss, GATA6 could now associate with FOG2 to form the GATA6-FOG2 complex to substitute for the missing GATA4-FOG2 partnership. If GATA4 ${ }^{\mathrm{ki}}$ isoform acts as a dominant negative and prevents GATA6-FOG2 complex from interacting with DNA, this complex may become active in the absence of GATA4 protein. While this will explain a milder phenotype of Sf1Cre; Gata4cKO animals compared with the Gata $4^{k i / k i}$, this possibility is remote. Before sexual differentiation, Fog2 gene deletion or Gata4 ${ }^{k i}$ mutation led to synonymous phenotype in $\mathrm{XY}$ or $\mathrm{XX}$ gonads arguing against dominant negative role for GATA4 ${ }^{\mathrm{ki}}$ (Tevosian et al. 2002, Manuylov et al. 2008). Moreover, the somatic cells of the developing testis exhibit no overt expression of other GATA family members (including GATA6) at least until E13.5 (unpublished observations).

The deletion of Gata4 by an Amhr2Cre (see below) was also reported (Kyrönlahti et al. 2011a). In contrast to the Gata4 deletions described earlier, no overt defects in embryonic or early postnatal testicular development in Amhr2Cre; Gata4 flox/flox males were observed. Gene expression in both Sertoli and Leydig cells was also normal. The absence of a prenatal testicular phenotype probably reflects the delayed or inefficient Amhr2Cremediated recombination in the embryonic and fetal testes. Notably, the reproductive organs of aged animals developed testicular atrophy and loss of fertility. The authors report Sertoli cell vacuolization and progressive tubule destruction with concomitant germ cell loss. In this respect, Wt1CreERT2 was also activated in the sexually mature adult animals to produce a Gata4 deletion in the testis. Wt1CreERT2-mediated deletion of Gata4 in the Sertoli cells of the adult organ was efficient but had no immediate deleterious effect on the testis appearance or spermatogenesis (Manuylov et al. 2011). These data strongly suggest an overlap of the functions of GATA proteins in the adult testis where all three GATA family members (GATA1, GATA4, and GATA6) are robustly expressed.

\section{GATA proteins in ovarian development}

Conspicuous expression of the Gata4 and Gata6 genes in the mouse ovary was discovered a number of years ago (Heikinheimo et al. 1997, Viger et al. 1998). Given the prominent roles attributed to GATA family members in the regulation of developmental gene expression, these proteins had long been suspected to have essential functions in the female gonad. Between the two proteins, the role for GATA4 in ovarian development and function is understood much better. As described earlier, gene expression analysis in mice carrying a Gata4 ${ }^{k i}$ mutation revealed that GATA4 and its transcription partner, FOG2, are required for establishing the ovarian differentiation program. While these studies provided important clues concerning GATA4's function in ovarian cells, the embryonic lethality of the global mutants limited the analysis of ovarian differentiation to the stages before birth. Conditional deletion using the Cre/Lox recombination system was critical in uncovering the role of GATA proteins in subsequent ovarian differentiation and function.

i) Sf1Cre-mediated loss of Gata4

Efimenko et al. (2013) used Sf1Cre-mediated gene targeting to determine the requirement for GATA4 and FOG2 in ovarian development and folliculogenesis. The results from this study identified an essential role for the GATA4 (but not FOG2) in the ovarian morphogenetic/differentiation program. This result is in stark contrast to the sex determination phase that requires both proteins for its correct execution. Although Gata4 was efficiently deleted in females shortly after sex determination, the effects of ovarian gene loss became most pronounced after birth. The conditional deletion of Gata4 within the embryonic ovary led to a decrease in granulosa and theca cell proliferation/recruitment as well as the depletion of primordial follicles in the ovarian cortex, causing a failure in follicular development. However, folliculogenesis was not completely extinguished in Sf1Cre; Gata4cKO ovaries, and a few GATA4deficient follicles developed to preantral stages when they became atretic. Adult Sf1Cre; Gata4cKO females developed ovarian cysts and were sterile (Efimenko et al. 2013).

ii) Amhr2Cre-mediated loss of Gata 4

Amhr2Cre was originally described by Behringer et al. (Jamin et al. 2002) and was one of the first available Cre lines that is active in embryonic gonads. The authors indicated that the activity of Cre recombinase was detected in the Müllerian duct mesenchyme and female gonads as early as E12.5 using the ROSA26 flox-stop-flox lacZ reporter $(R 26 R)$ mice. For the past decade, this Cre line has been used successfully by many investigators to delete or activate their gene of interest in cells of the reproductive system.

Kyrönlahti et al. $(2011 a, b)$ produced

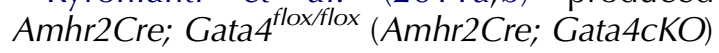


mice (Kyrönlahti et al. 2011b). While ovarian development appeared overtly normal in young animals, the authors noted impaired fertility and cystic ovarian changes in aged females. Upon gonadotropin stimulation, immature Amhr2Cre; Gata4cKO mice released fewer oocytes. These findings were similar to those that the authors observed in Gata4 ${ }^{+/-}$(germline heterozygous) animals. Compared with WT mice, the ovaries of gonadotropin-stimulated $\mathrm{Gata4}^{+/-}$mice were smaller, released fewer oocytes, and produced less estrogen. In stimulated $\mathrm{Gata}^{+}{ }^{+}$animals, the authors observed a downregulation in the expression of the putative GATA4 target genes Star, Cyp11a1, and Cyp19a1. In contrast, the only significantly downregulated gene in the Amhr2Cre; Gata4cKO animals was Cyp19a1.

To better interpret the results of this Cre/Lox experiment, the authors carefully examined the pattern of Amhr2Cre-mediated R26R excision within ovaries. While the authors confirmed that the Amhr2Cre transgene directs Cre expression to granulosa cells in secondary follicles, the expression was not uniform, with both lacZpositive and lacZ-negative granulosa cells present. The variable Cre expression in granulosa cells likely contributed to the variable penetrance of the phenotype in Amhr2Cre; Gata4cKO mice. In post-pubertal mutant animals, the GATA4 protein was still present in theca cells and granulosa cells of primary, preantral, and antral follicles. The authors concluded that the extensive residual GATA4 activity presumably reflects cells in which the Amhr2Cre did not inactivate both Gata $4^{\text {flox }}$ alleles.

iii) Double inactivation of the Gata4 and Gata6 genes The Cyp19Cre transgenic mice drive Cre expression from the 304 bp Cyp19a1 (aromatase) promoter (Fan et al. 2008, 2009). To monitor Cre recombination in ovaries, Cyp19Cre mice were crossed with the $R 26 R$ reporter strain. Robust Cre activity was present in the granulosa cells in antral follicles and in luteal cells; Cre activity was low or undetectable in all immature follicles, theca cells, and oocytes. The activities of Amhr2Cre and Cyp19Cre were compared directly in their ability to induce recombination of KrasG12D in the ovary (Fan et al. 2008). The authors demonstrated that Cyp19Cre is expressed later in development compared with Amhr2Cre, with no Cyp19Cre-induced recombination observed before PND 10 (Fan et al. 2008).

The role of GATA4 within the ovary has been studied by using three conditional mutant models (Amhr2Cre, Cyp19Cre, or Sf1Cre where Cyp19Cre and Amhr2Cre are active postnatally, and Sf1Cre is active embryonically).
The severity of follicular development disruption varied in the ovaries from animals that underwent GATA4 loss through these different courses. However, all mutant mice had an abnormal response to exogenous gonadotropins and the presence of ovarian cysts was frequently observed (Kyrönlahti et al. 2011 b, Bennett et al. 2012, Efimenko et al. 2013). In all cases, mutant females were either sub-fertile or infertile. The variations found among these phenotypes can be largely attributed to the completeness of the deletion in granulosa cells and the time when Cre recombination occurred. The earliest excision timing for Sf1Cre at E12.5 could be essential due to the emerging expression of GATA6 at E13.5 that partially compensates for ovarian follicular development in the absence of GATA4 (Kyrönlahti et al. 2011 b, Bennett et al. 2012, Efimenko et al. 2013).

Recently, a mutant line harboring a deletion of Gata4 and Gata6 within the ovary using the Cyp19Cre line has been produced by Bennett et al. (2012). Not surprisingly, given the Cyp19Cre expression pattern, primary and multilayer follicles were present in ovaries from Cyp19Cre; Gata4 ${ }^{\text {flox/-}}$; Gata6 flox/flox females, but large pre-ovulatory follicles or corpora lutea were not formed (Bennett et al. 2012). Moreover, abnormal estrous cycle and infertility were noticed in Cyp19Cre; Gata4 $4^{\text {flox } /-}$; Gata6 $6^{\text {flox/flox }}$ females. The authors also examined fertility in the single mutants and observed subfertility in Cyp19Cre; Gata $4^{\text {flox/- }}$ mice, while normal reproductive function was noted in Cyp19Cre; Gata6 flox/- animals.

The follow-up work by Bennett et al. (2013) attempted to delineate the pathways regulated by GATA factors in adult granulosa cells (Bennett et al. 2013). Microarray analyses compared gene expression patterns in WT animals, single conditional mutants, and double conditional mutants after in vivo treatment with equine chorionic gonadotropin. In line with their previous observations, the authors confirmed that GATA4 is a dominant regulatory GATA factor in granulosa cells. Cyp19Cremediated Gata4 gene deletion affected a greater number of genes than Gata6 deletion. An even greater number of genes were affected by the deletion of both transcription factors. The authors demonstrated that GATA4 and GATA6 functionally compensate for each other in the regulation of key ovarian genes. When compared with single GATA-deficient animals, the change in the expression of numerous genes critical for ovarian function (e.g. Fshr, Lhcgr, Inha, Inhbb, versican, pregnancy-associated plasma protein $A$, and the regulatory unit $2 b$ of protein kinase A) was much more 
pronounced in the double conditional mutant Rescue experiments involving the treatment of cultured granulosa cells with cAMP or insulinlike growth factor 1 (IGF1) to circumvent follicle-stimulating hormone and IGF1 signaling defects were largely inefficient, confirming that most of the affected genes are regulated by GATA factors directly (Bennett et al. 2013).

In a complementary approach, Padua et al. (2013, unpublished results) deleted both genes (Gata4 and Gata6) within the ovary by using Sf1Cre (conditional double mutant). Embryonic loss of both GATA factors produced an early ovarian phenotype with a marked reduction in the expression of genes involved in ovarian development (e.g. Foxl2, Fst, and Irx3). In addition, neonatal conditional double mutant ovaries contained no follicles beyond primordial stage, suggesting a block in follicular development that is caused by an impaired somatic cell proliferation. Moreover, only rare oocytes survive in ovaries from conditional double mutant females and most of them disappear before animals reach puberty. The results from this study demonstrate the key roles of GATA4 and GATA6 in mammalian ovary development, cell proliferation, and folliculogenesis.

\section{Conclusion}

The combination of a conditional gene knockout and subsequent unbiased analysis of gene expression (e.g. microarray) has become a fundamental approach in understanding protein function. Early on, the elegant austerity of a knockout technology stirred expectations that these genetic experiments will provide absolute solutions. Now, it is becoming increasingly clear that even the most comprehensive answers require further qualifications, and what information can be gleaned from targeting genes in vivo is limited. Some of the important points one has to consider in interpreting the results of a gene targeting experiment are discussed below. The detailed characterization of Cre lines is an obligatory part of the gene targeting experiment, and its importance cannot be overemphasized. Comparisons of phenotypic and molecular outcomes generated by germline gene targeting and multiple Cre enzymes (as outlined for Gata genes in Fig. 1) will be helpful in describing the complexity of reproductive genetics.

\section{Cre excision: location and efficiency considerations}

In evaluating the results of a gene targeting experiment, the excision location and efficiency for each developmental stage need to be determined precisely. As described above, this analysis is normally performed in advance of the actual 'gene-of-interest' experiment using a ROSA26 lacZ reporter (R26R) in place of the gene. A ROSA $\mathrm{mT} / \mathrm{mG}$ reporter has been used more recently for the same purpose. In this reporter line, the excision of the stop cassette switches the fluorescent gene product from red to green in the excised cells (Muzumdar et al. 2007).

The use of different Reporter lines for the same Cre may provide valuable additional clues to the expected excision pattern. For example, Deutscher \& Hung-Chang Yao (2007) crossed the Amhr2Cre line with the Cre reporter line Z/EG or B6.Cg-Tg(ACTB-Bgeo/GFP)21Lbe, which expresses EGFP upon Cre-induced recombination. The authors reported that EGFP expression began to appear only at E15.5, about $72 \mathrm{~h}$ later than originally described (Jamin et al. 2002), and was mostly restricted to the Müllerian duct mesenchyme with very few EGFPpositive cells present in the ovary. The authors proposed that the delay in the detection of Amhr2Cre activity could result from the time required for proper EGFP folding or the accessibility of the reporter construct to the Cre recombinase. Similarly, Jorgez et al. (2004) used the Amhr2Cre line to ablate the Fst gene in the granulosa cells of the ovary (Jorgez et al. 2004). The authors evaluated Cre activity in the postnatal ovaries by crossing the Amhr2Cre mice with R26R. After X-gal staining, the authors detected $\beta$-gal activity in the E17.5 ovaries of Amhr2Cre; R26R double heterozygous females, but the $\beta$-gal activity appeared to be fairly low. Furthermore, in the postnatal ovary, $\beta$-gal activity was abundant in the granulosa cells of all secondary and small antral follicles but was at much lower or undetectable levels in granulosa cells of primordial and primary follicles. These observations are consistent with the endogenous Amhr2 expression pattern and introduce several possibilities one has to consider in choosing this Cre line: Amhr2Cre activity may become efficient fairly late (past E15.5) in ovary development, Amhr2Cre activity may be gene-dependent, or the timing of Amhr2Cre activity may depend on the animal background or some other non-traceable genetic variable.

Another important factor to consider is off-target expression. In the same study (Jorgez et al. 2004), low Cre activity was found in some theca cells and oocytes. Others have demonstrated that in addition to its ovarian expression, Amhr2Cre is expressed in additional reproductive tissues, including ovarian surface epithelial cells and the uterus (Boerboom et al. 2005, Fan et al. 2008, Hernandez Gifford et al. 2009). The activity of another popular Cre, Sf1Cre, in the pituitary and hypothalamus (Bingham etal. 2006) may also be of concern in evaluating adult reproductive outcomes, especially if a targeted gene is ubiquitously expressed. While early follicular development is gonadotropin-independent, gonadal pathology and abnormal folliculogenesis in the adult animals may result from the extra-gonadal gene loss. This possibility should not be automatically discounted. 
Regardless of the excision pattern observed in the Cre reporter experiment, these results should only serve as an advisory preview guide in selecting an appropriate Cre, as the recombination efficiency for a gene of interest may differ from that of the ROSA locus and should always be tested separately. This consideration is especially true for the inducible Cre lines (e.g. tamoxifen-activated), and one needs to be aware of the possibility of animal-

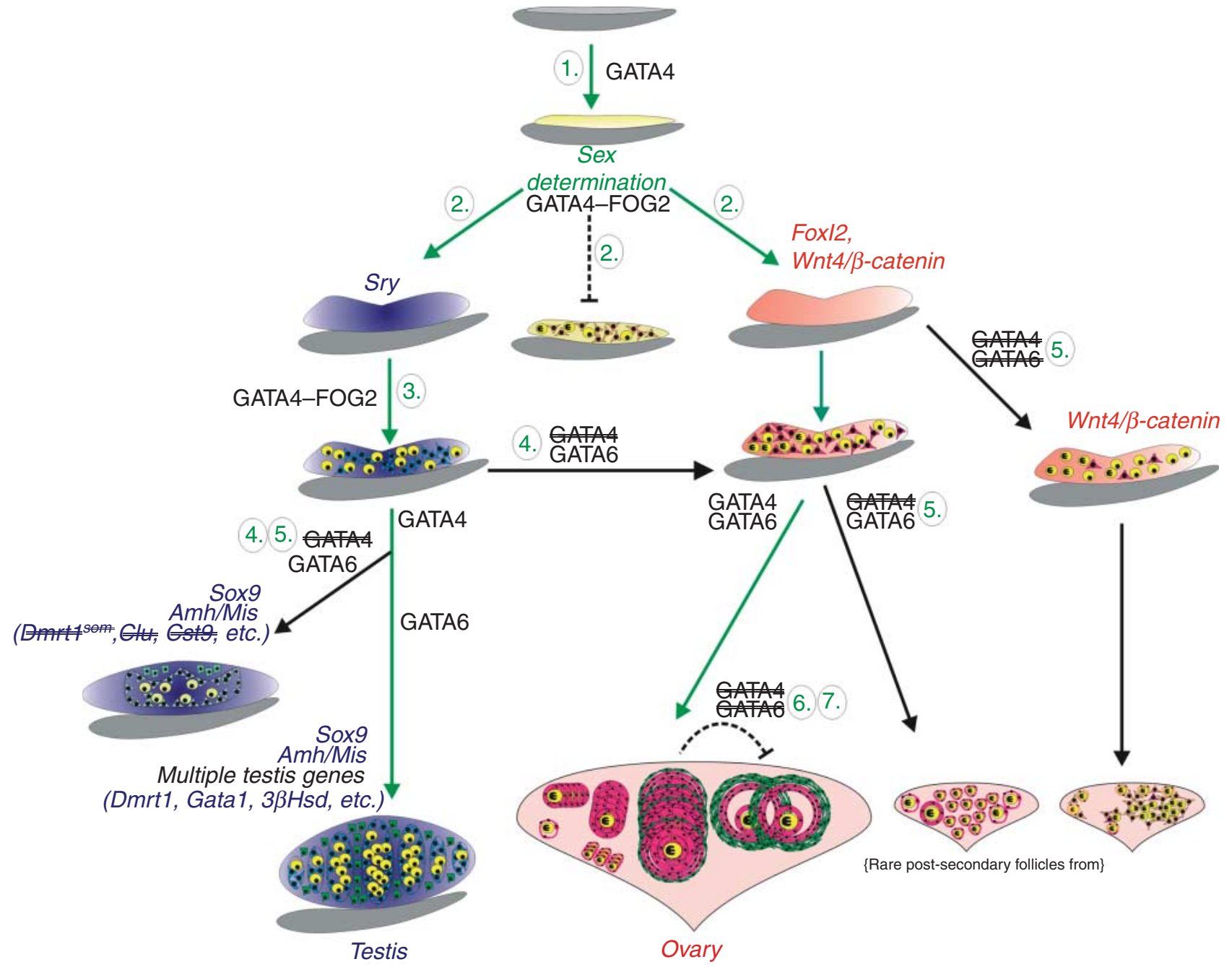

Figure 1 Transgenic approaches to defining GATA protein function in murine sexual development. Before sex determination stage GATA4 is required to initiate the formation of the genital ridge in the bipotential gonad. Subsequent sexual determination and activation of XY and XX sex-specific gene expression programs require GATA4-FOG2 complex. In males, GATA4-FOG2 complex function is essential for, but not limited to, Sry activation and this partnership remains active during subsequent sexual differentiation. GATA4 is required to establish Sertoli cell identity and Gata4 gene ablation (represented by double strikethrough) during sex determination stage leads to a male-to-female sex reversal. Loss of GATA4 in pre-Sertoli cells shortly after sex determination is compatible with testis formation; however, Sertoli-specific genes that continuously require GATA for their expression are no longer maintained (e.g. Dmrt1). In females, the embryonic loss of GATA4 results in germ cell demise, postnatal block in granulosa cell proliferation, and severely curtailed follicular development. The embryonic loss of both GATA4 and GATA6 factors (double strikethrough) is markedly more detrimental, with drastically reduced numbers of pre-granulosa cells and follicular block at the primordial stage in the mutant animals. Targeting Gata genes in granulosa cells of the secondary follicles disrupts subsequent follicular maturation and leads to sterility. Globally targeted, transgenic, floxed, and Cre lines used for these experiments are listed below. The original publications describing the transgenic lines as well as the publications $\left(^{*}\right)$ describing specific applications discussed in the review are referenced. Note that three different lines carrying Gata4floxed allele are available. (1) Cre/Lox, Gata4 floxfflox (Watt et al. 2004), CAG-CreER (Hayashi \& McMahon 2002), WT1_CreERT2 (Zhou et al. 2008), and Osr $1^{\text {eGFP-CreERt2 (Mugford et al. 2008, Hu et al. 2013*). (2) Fog2 }}{ }^{-/-}$(Tevosian et al. 2000), Gata4 ${ }^{k i / k i}$ (Crispino et al. 2001), and MyHC-FOG2 (Tevosian et al. 2002, Manuylov et al. 2008)*. (3) Fog2 ${ }^{-/-}$(Tevosian et al. 2000), Gata4 ${ }^{k i k i}$ (Crispino et al. 2001), MyHC-FOG2 (Tevosian et al. 2002), Wt1-Sox9 (Vidal et al. 2001), and Ods (Bishop et al. 1999) (Tevosian et al. 2002, Bouma et al. 2007, Manuylov et al. 2007a, 2008)*. (4) Cre/Lox, Gata4 floxflox (Watt et al. 2004), Gata4 floxfflox (Zeisberg et al. 2005), and Wt1ERT2Cre (Zhou et al. 2008, Manuylov et al. 2011*). (5) Cre/Lox, Sf1Cre (Bingham et al. 2006), Gata4 flox/flox (Zeisberg et al. 2005), Gata4 flox/flox (Watt et al. 2004), Gata4 flap/flap (Ma et al. 2008),

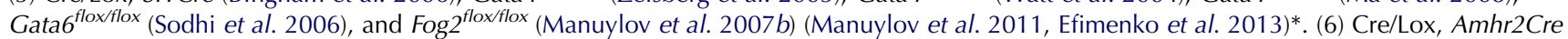
(Jamin et al. 2002) and Gata4tlox/flox (Watt et al. 2004, Kyrönlahti et al. 2011b*). (7) Cre/Lox, Cyp19Cre (Fan et al. 2008), Gata4 ${ }^{\text {flox/flox }}$ (Watt et al. 2004), and Gata6 floxflox (Sodhi et al. 2006) (Bennett et al. 2012, 2013)*. 
to-animal variation due to the variability of injection efficiency or lot variations in drug potency. If gene excision in a plainly homogenous cell population remains incomplete, the decision of whether one still proceeds with the analysis of the phenotype is not an easy one. While the evaluation of a partial excision can still lead to valuable information, the interpretation of the results could be cumbersome, and a different choice of Cre line may be more prudent in these circumstances.

In the past decade, the conditional knockout technology in mice has matured into an indispensable part of the armamentarium for genetic analysis. The increased availability of mouse lines carrying 'floxed' genes and Cre recombinases from public repositories has allowed for the widespread use of this technology in numerous laboratories across the world. The analysis of reproductive outcomes (phenotypes) of Cre-mediated gene deletions in mice has been extremely helpful in expanding our understanding of reproductive development. While global gene knockouts were key in elucidating the functions of many genes in the reproductive system, these studies were limited, especially for genes required for survival during embryogenesis. The loss-of-function mutations in these genes led to early embryonic phenotypes and often lethality, thus precluding a thorough examination of their roles in organs that are non-essential for viability. The conditional gene knockouts became less of a risky undertaking than the global/germline knockouts, as the outcome of the gene modification is no longer dictated by the 'weakest link', but could be steered in a reasonably predictable manner toward differentiated adult tissues.

Theoretically, a gene loss that is limited to a defined cell type should simplify the interpretation of the outcome. However, gene regulation clearly remains highly time- and context-dependent. Once the cell has lost one or two of its major regulatory genes, a definition of the 'cell type' is becoming much more fluid and is in flux. Instead of delivering succinct diagrams, transgenic approaches have led to a more comprehensive and nuanced understanding of genetic interactions. These 'methods of questioning' have also revealed a need for new definitions of gene function that are temporally and spatially confined.

\section{Declaration of interest}

The authors declare that there is no conflict of interest that could be perceived as prejudicing the impartiality of the review.

\section{Funding}

This research was supported by the NIH (NICHD), USA, HD042751.

\section{References}

Anttonen M, Ketola I, Parviainen H, Pusa AK \& Heikinheimo M 2003 FOG-2 and GATA-4 are coexpressed in the mouse ovary and can modulate Müllerian-inhibiting substance expression. Biology of Reproduction 68 1333-1340. (doi:10.1095/biolreprod.102.008599)

Anttonen M, Parviainen H, Kyrönlahti A, Bielinska M, Wilson DB, Ritvos O \& Heikinheimo $\mathbf{M} 2006$ GATA-4 is a granulosa cell factor employed in inhibin-alpha activation by the TGF- $\beta$ pathway. Journal of Molecular Endocrinology 36 557-568. (doi:10.1677/jme.1.01962)

Bailey RW, Aronow B, Harmony JA \& Griswold MD 2002 Heat shockinitiated apoptosis is accelerated and removal of damaged cells is delayed in the testis of clusterin/Apol knock-out mice. Biology of Reproduction 66 1042-1053. (doi:10.1095/biolreprod66.4.1042)

Bennett J, Wu YG, Gossen J, Zhou P \& Stocco C 2012 Loss of GATA-6 and GATA-4 in granulosa cells blocks folliculogenesis, ovulation, and follicle stimulating hormone receptor expression leading to female infertility. Endocrinology 153 2474-2485. (doi:10.1210/en.2011-1969)

Bennett J, Baumgarten SC \& Stocco C 2013 GATA4 and GATA6 silencing in ovarian granulosa cells affects levels of mRNAs involved in steroidogenesis, extracellular structure organization, IGF-I activity, and apoptosis. Endocrinology 154 4845-4858. (doi:10.1210/en.2013-1410)

Bhardwaj A, Rao MK, Kaur R, Buttigieg MR \& Wilkinson MF 2008 GATA factors and androgen receptor collaborate to transcriptionally activate the Rhox5 homeobox gene in Sertoli cells. Molecular and Cellular Biology 28 2138-2153. (doi:10.1128/MCB.01170-07)

Bingham NC, Verma-Kurvari S, Parada LF \& Parker KL 2006 Development of a steroidogenic factor $1 /$ Cre transgenic mouse line. Genesis 44 419-424. (doi:10.1002/dvg.20231)

Bishop CE, Whitworth DJ, Qin Y, Agoulnik AI, Agoulnik IU, Harrison WR, Behringer RR \& Overbeek PA 1999 A transgenic insertion upstream of Sox9 is associated with dominant XX sex reversal in the mouse. Nature Genetics 26 490-494. (doi:10.1038/82652)

Boerboom D, Paquet M, Hsieh M, Liu J, Jamin SP, Behringer RR, Sirois J, Taketo MM \& Richards JS 2005 Misregulated Wnt/ $\beta$-catenin signaling leads to ovarian granulosa cell tumor development. Cancer Research 65 9206-9215. (doi:10.1158/0008-5472.CAN-05-1024)

Bouma GJ, Washburn LL, Albrecht KH \& Eicher EM 2007 Correct dosage of Fog2 and Gata4 transcription factors is critical for fetal testis development in mice. PNAS 104 14994-14999. (doi:10.1073/pnas. 0701677104)

Buganim Y, Itskovich E, Hu YC, Cheng AW, Ganz K, Sarkar S, Fu D, Welstead GG, Page DC \& Jaenisch R 2012 Direct reprogramming of fibroblasts into embryonic Sertoli-like cells by defined factors. Cell Stem Cell 11 373-386. (doi:10.1016/j.stem.2012.07.019)

Bullejos M \& Koopman P 2005 Delayed Sry and Sox9 expression in developing mouse gonads underlies B6-Y(DOM) sex reversal. Developmental Biology 278 473-481. (doi:10.1016/j.ydbio.2004.11.030)

Cai Z, Kwintkiewicz J, Young ME \& Stocco C 2007 Prostaglandin E2 increases cyp19 expression in rat granulosa cells: implication of GATA-4. Molecular and Cellular Endocrinology 263 181-189. (doi:10.1016/j.mce.2006.09.012)

Cantor AB \& Orkin SH 2005 Coregulation of GATA factors by the Friend of GATA (FOG) family of multitype zinc finger proteins. Seminars in Cell \& Developmental Biology 16 117-128. (doi:10.1016/j.semcdb. 2004.10.006)

Carrasco M, Delgado I, Soria B, Martin F \& Rojas A 2012 GATA4 and GATA6 control mouse pancreas organogenesis. Journal of Clinical Investigation 122 3504-3515. (doi:10.1172/JCl63240)

Chlon TM \& Crispino JD 2012 Combinatorial regulation of tissue specification by GATA and FOG factors. Development 139 3905-3916. (doi:10.1242/dev.080440)

Costantini F \& Lacy E 1981 Introduction of a rabbit $\beta$-globin gene into the mouse germ line. Nature 294 92-94. (doi:10.1038/294092a0)

Crispino JD, Lodish MB, Mackay JP \& Orkin SH 1999 Use of altered specificity mutants to probe a specific protein-protein interaction in differentiation: the GATA-1:FOG complex. Molecular Cell 3 219-228. (doi:10.1016/S1097-2765(00)80312-3)

Crispino JD, Lodish MB, Thurberg BL, Litovsky SH, Collins T, Molkentin JD \& Orkin SH 2001 Proper coronary vascular development and heart morphogenesis depend on interaction of GATA-4 with FOG cofactors. Genes and Development 15 839-844. (doi:10.1101/gad.875201) 
Defalco T, Takahashi S \& Capel B 2011 Two distinct origins for Leydig cell progenitors in the fetal testis. Developmental Biology 352 14-26. (doi:10.1016/j.ydbio.2011.01.011)

Deutscher E \& Hung-Chang Yao H 2007 Essential roles of mesenchymederived $\beta$-catenin in mouse Müllerian duct morphogenesis. Developmental Biology 307 227-236. (doi:10.1016/j.ydbio.2007.04.036)

Efimenko E, Padua MB, Manuylov NL, Fox SC, Morse DA \& Tevosian SG 2013 The transcription factor GATA4 is required for follicular development and normal ovarian function. Developmental Biology 381 144-158. (doi:10.1016/j.ydbio.2013.06.004)

Fan HY, Shimada M, Liu Z, Cahill N, Noma N, Wu Y, Gossen J \& Richards JS 2008 Selective expression of KrasG12D in granulosa cells of the mouse ovary causes defects in follicle development and ovulation. Development 135 2127-2137. (doi:10.1242/dev.020560)

Fan HY, Liu Z, Paquet M, Wang J, Lydon JP, DeMayo FJ \& Richards JS 2009 Cell type-specific targeted mutations of Kras and Pten document proliferation arrest in granulosa cells versus oncogenic insult to ovarian surface epithelial cells. Cancer Research 69 6463-6472. (doi:10.1158/ 0008-5472.CAN-08-3363)

Feng ZM, Wu AZ, Zhang Z \& Chen CL 2000 GATA-1 and GATA-4 transactivate inhibin/activin beta-B-subunit gene transcription in testicular cells. Molecular Endocrinology 14 1820-1835.

Fujiwara Y, Browne CP, Cunniff K, Goff SC \& Orkin SH 1996 Arrested development of embryonic red cell precursors in mouse embryos lacking transcription factor GATA-1. PNAS 93 12355-12358. (doi:10.1073/pnas. 93.22.12355)

Gubbay J, Collignon J, Koopman P, Capel B, Economou A, Munsterberg A, Vivian N, Goodfellow P \& Lovell-Badge R 1990 A gene mapping to the sex-determining region of the mouse $\mathrm{Y}$ chromosome is a member of a novel family of embryonically expressed genes. Nature 346 245-250. (doi:10.1038/346245a0)

Hasegawa K, Chuma S, Tada T, Sakurai T, Tamura M, Suemori H \& Nakatsuji N 2006 Testatin transgenic and knockout mice exhibit normal sex-differentiation. Biochemical and Biophysical Research Communications 341 369-375. (doi:10.1016/j.bbrc.2005.12.183)

Hayashi S \& McMahon AP 2002 Efficient recombination in diverse tissues by a tamoxifen-inducible form of Cre: a tool for temporally regulated gene activation/inactivation in the mouse. Developmental Biology $\mathbf{2 4 4}$ 305-318. (doi:10.1006/dbio.2002.0597)

Heikinheimo M, Ermolaeva M, Bielinska M, Rahman NA, Narita N, Huhtaniemi IT, Tapanainen JS \& Wilson DB 1997 Expression and hormonal regulation of transcription factors GATA-4 and GATA- 6 in the mouse ovary. Endocrinology 138 3505-3514.

Hernandez Gifford JA, Hunzicker-Dunn ME \& Nilson JH 2009 Conditional deletion of $\beta$-catenin mediated by Amhr2cre in mice causes female infertility. Biology of Reproduction 80 1282-1292. (doi:10.1095/ biolreprod.108.072280)

Hiramatsu R, Matoba S, Kanai-Azuma M, Tsunekawa N, Katoh-Fukui Y, Kurohmaru M, Morohashi K, Wilhelm D, Koopman P \& Kanai Y 2009 A critical time window of Sry action in gonadal sex determination in mice. Development 136 129-138. (doi:10.1242/dev.029587)

Hu YC, Okumura LM \& Page DC 2013 Gata4 is required for formation of the genital ridge in mice. PLoS Genetics 9 e1003629. (doi:10.1371/ journal.pgen.1003629)

Huang CC \& Yao HH 2010 Inactivation of Dicer1 in steroidogenic factor 1-positive cells reveals tissue-specific requirement for Dicer1 in adrenal, testis, and ovary. BMC Developmental Biology 1066. (doi:10.1186/1471-213X-10-66)

Imai T, Kawai $Y$, Tadokoro $Y$, Yamamoto $M$, Nishimune $Y$ \& Yomogida $K$ 2004 In vivo and in vitro constant expression of GATA-4 in mouse postnatal Sertoli cells. Molecular and Cellular Endocrinology 214 107-115. (doi:10.1016/j.mce.2003.10.065)

Jamin SP, Arango NA, Mishina Y, Hanks MC \& Behringer RR 2002 Requirement of Bmpr1a for Müllerian duct regression during male sexual development. Nature Genetics 32 408-410. (doi:10.1038/ng1003)

Jensen P \& Dymecki SM 2014 Essentials of recombinase-based genetic fate mapping in mice. Methods in Molecular Biology 1092 437-454. (doi:10.1007/978-1-60327-292-6_26)

Jorgez CJ, Klysik M, Jamin SP, Behringer RR \& Matzuk MM 2004 Granulosa cell-specific inactivation of follistatin causes female fertility defects. Molecular Endocrinology 18 953-967. (doi:10.1210/me.2003-0301)
Kaisman-Elbaz T, Sekler I, Fishman D, Karol N, Forberg M, Kahn N, Hershfinkel M \& Silverman WF 2009 Cell death induced by zinc and cadmium is mediated by clusterin in cultured mouse seminiferous tubules. Journal of Cellular Physiology 220 222-229. (doi:10.1002/jcp.21754)

Kashimada K \& Koopman P 2010 Sry: the master switch in mammalian sex determination. Development 137 3921-3930. (doi:10.1242/dev. 048983)

Ketola I, Rahman N, Toppari J, Bielinska M, Porter-Tinge SB, Tapanainen JS, Huhtaniemi IT, Wilson DB \& Heikinheimo M 1999 Expression and regulation of transcription factors GATA-4 and GATA- 6 in developing mouse testis. Endocrinology 140 1470-1480.

Kim Y, Bingham N, Sekido R, Parker KL, Lovell-Badge R \& Capel B 2007a Fibroblast growth factor receptor 2 regulates proliferation and Sertoli differentiation during male sex determination. PNAS 104 16558-16563. (doi:10.1073/pnas.0702581104)

Kim S, Bardwell VJ \& Zarkower D 2007b Cell type-autonomous and nonautonomous requirements for Dmrt1 in postnatal testis differentiation. Developmental Biology 307 314-327. (doi:10.1016/j.ydbio.2007.04.046)

Kim AC, Reuter AL, Zubair M, Else T, Serecky K, Bingham NC, Lavery GG, Parker KL \& Hammer GD 2008 Targeted disruption of $\beta$-catenin in Sf1expressing cells impairs development and maintenance of the adrenal cortex. Development 135 2593-2602. (doi:10.1242/dev.021493)

Koutsourakis M, Langeveld A, Patient R, Beddington R \& Grosveld F 1999 The transcription factor GATA6 is essential for early extraembryonic development. Development 126 723-732.

Kuo CT, Morrisey EE, Anandappa R, Sigrist K, Lu MM, Parmacek MS, Soudais C \& Leiden JM 1997 GATA4 transcription factor is required for ventral morphogenesis and heart tube formation. Genes and Development 11 1048-1060. (doi:10.1101/gad.11.8.1048)

Kyrönlahti A, Euler R, Bielinska M, Schoeller EL, Moley KH, Toppari J, Heikinheimo M \& Wilson DB 2011a GATA4 regulates Sertoli cell function and fertility in adult male mice. Molecular and Cellular Endocrinology 333 85-95. (doi:10.1016/j.mce.2010.12.019)

Kyrönlahti A, Vetter $M$, Euler R, Bielinska $M$, Jay PY, Anttonen $M$, Heikinheimo M \& Wilson DB 2011b GATA4 deficiency impairs ovarian function in adult mice. Biology of Reproduction 84 1033-1044. (doi:10. 1095/biolreprod.110.086850)

Lander ES, Linton LM, Birren B, Nusbaum C, Zody MC, Baldwin J, Devon K, Dewar K, Doyle M, FitzHugh W et al. 2001 Initial sequencing and analysis of the human genome. Nature $\mathbf{4 0 9} 860-921$. (doi:10.1038/ 35057062)

LaVoie HA 2003 The role of GATA in mammalian reproduction. Experimental Biology and Medicine 228 1282-1290.

Lavoie HA \& King SR 2009 Transcriptional regulation of steroidogenic genes: STARD1, CYP11A1 and HSD3B. Experimental Biology and Medicine 234 880-907. (doi:10.3181/0903-MR-97)

Lavoie HA, McCoy GL \& Blake CA 2004 Expression of the GATA-4 and GATA- 6 transcription factors in the fetal rat gonad and in the ovary during postnatal development and pregnancy. Molecular and Cellular Endocrinology 227 31-40. (doi:10.1016/j.mce.2004.07.016)

Lei N \& Heckert LL 2004 Gata4 regulates testis expression of Dmrt1. Molecular and Cellular Biology 24 377-388. (doi:10.1128/MCB.24.1. 377-388.2004)

Lei N, Karpova T, Hornbaker KI, Rice DA \& Heckert LL 2009 Distinct transcriptional mechanisms direct expression of the rat Dmrt1 promoter in Sertoli cells and germ cells of transgenic mice. Biology of Reproduction 81 118-125. (doi:10.1095/biolreprod.108.072314)

Lindeboom F, Gillemans N, Karis A, Jaegle M, Meijer D, Grosveld F \& Philipsen S 2003 A tissue-specific knockout reveals that Gata1 is not essential for Sertoli cell function in the mouse. Nucleic Acids Research 31 5405-5412. (doi:10.1093/nar/gkg723)

Lu JR, McKinsey TA, Xu H, Wang DZ, Richardson JA \& Olson EN 1999 FOG-2, a heart- and brain-enriched cofactor for GATA transcription factors. Molecular and Cellular Biology 19 4495-4502.

Ma Q, Zhou B \& Pu WT 2008 Reassessment of Is/1 and Nkx2-5 cardiac fate maps using a Gata4-based reporter of Cre activity. Developmental Biology 323 98-104. (doi:10.1016/j.ydbio.2008.08.013)

Mali P, Esvelt KM \& Church GM 2013 Cas9 as a versatile tool for engineering biology. Nature Methods 10 957-963. (doi:10.1038/ nmeth.2649) 
Manuylov NL, Fujiwara Y, Adameyko II, Poulat F \& Tevosian SG 2007a The regulation of Sox9 gene expression by the GATA4/FOG2 transcriptional complex in dominant XX sex reversal mouse models. Developmental Biology 307 356-367. (doi:10.1016/j.ydbio.2007.04.040)

Manuylov NL, Smagulova FO \& Tevosian SG 2007b Fog2 excision in mice leads to premature mammary gland involution and reduced Esr1 gene expression. Oncogene 26 5204-5213. (doi:10.1038/sj.onc.1210333)

Manuylov NL, Smagulova FO, Leach L \& Tevosian SG 2008 Ovarian development in mice requires the GATA4-FOG2 transcription complex. Development 135 3731-3743. (doi:10.1242/dev.024653)

Manuylov NL, Zhou B, Ma Q, Fox SC, Pu WT \& Tevosian SG 2011 Conditional ablation of Gata4 and Fog2 genes in mice reveals their distinct roles in mammalian sexual differentiation. Developmental Biology 353 229-241. (doi:10.1016/j.ydbio.2011.02.032)

Martin LJ, Bergeron F, Viger RS \& Tremblay JJ 2012 Functional cooperation between GATA factors and cJUN on the Star promoter in MA-10 Leydig cells. Journal of Andrology 33 81-87. (doi:10.2164/jandrol.110.012039)

Matson CK, Murphy MW, Sarver AL, Griswold MD, Bardwell VJ \& Zarkower D 2011 DMRT1 prevents female reprogramming in the postnatal mammalian testis. Nature 476 101-104. (doi:10.1038/ nature10239)

Matsuda M, Nagahama Y, Shinomiya A, Sato T, Matsuda C, Kobayashi T, Morrey CE, Shibata N, Asakawa S, Shimizu N et al. 2002 DMY is a $\mathrm{Y}$-specific DM-domain gene required for male development in the medaka fish. Nature 417 559-563. (doi:10.1038/nature751)

Molkentin JD 2000 The zinc finger-containing transcription factors GATA-4, -5 , and -6. Ubiquitously expressed regulators of tissue-specific gene expression. Journal of Biological Chemistry 275 38949-38952. (doi:10.1074/jbc.R000029200)

Molkentin JD, Lin Q, Duncan SA \& Olson EN 1997 Requirement of the transcription factor GATA4 for heart tube formation and ventral morphogenesis. Genes and Development 11 1061-1072. (doi:10.1101/ gad.11.8.1061)

Mugford JW, Sipila P, McMahon JA \& McMahon AP 2008 Osr1 expression demarcates a multi-potent population of intermediate mesoderm that undergoes progressive restriction to an Osr1-dependent nephron progenitor compartment within the mammalian kidney. Developmental Biology 324 88-98. (doi:10.1016/j.ydbio.2008.09.010)

Muzumdar MD, Tasic B, Miyamichi K, Li L \& Luo L 2007 A global double-fluorescent Cre reporter mouse. Genesis 45 593-605. (doi:10. 1002/dvg.20335)

Nishida H, Miyagawa S, Vieux-Rochas M, Morini M, Ogino Y, Suzuki K, Nakagata N, Choi HS, Levi G \& Yamada G 2008 Positive regulation of steroidogenic acute regulatory protein gene expression through the interaction between Dlx and GATA-4 for testicular steroidogenesis. Endocrinology 149 2090-2097. (doi:10.1210/en.2007-1265)

Patient RK \& McGhee JD 2002 The GATA family (vertebrates and invertebrates). Current Opinion in Genetics \& Development 12 416-422. (doi:10.1016/S0959-437X(02)00319-2)

Pennisi E 2012 The tale of the TALEs. Science 338 1408-1411. (doi:10.1126/science.338.6113.1408)

Rahman NA, Kiiveri S, Rivero-Muller A, Levallet J, Vierre S, Kero J, Wilson DB, Heikinheimo M \& Huhtaniemi I 2004 Adrenocortical tumorigenesis in transgenic mice expressing the inhibin alpha-subunit promoter/simian virus $40 \mathrm{~T}$-antigen transgene: relationship between ectopic expression of luteinizing hormone receptor and transcription factor GATA-4. Molecular Endocrinology 18 2553-2569. (doi:10.1210/ me.2002-0282

Raymond CS, Shamu CE, Shen MM, Seifert KJ, Hirsch B, Hodgkin J \& Zarkower D 1998 Evidence for evolutionary conservation of sex-determining genes. Nature 391 691-695. (doi:10.1038/35618)

Raymond CS, Parker ED, Kettlewell JR, Brown LG, Page DC, Kusz K, Jaruzelska J, Reinberg Y, Flejter WL, Bardwell VJ et al. 1999 A region of human chromosome $9 p$ required for testis development contains two genes related to known sexual regulators. Human Molecular Genetics 8 989-996. (doi:10.1093/hmg/8.6.989)

Raymond CS, Murphy MW, O'Sullivan MG, Bardwell VJ \& Zarkower D $2000 \mathrm{Dmrt1}$, a gene related to worm and fly sexual regulators, is required for mammalian testis differentiation. Genes and Development 14 2587-2595. (doi:10.1101/gad.834100)
Robert NM, Tremblay JJ \& Viger RS 2002 Friend of GATA (FOG)-1 and FOG-2 differentially repress the GATA-dependent activity of multiple gonadal promoters. Endocrinology 143 3963-3973. (doi:10.1210/en.2002-220280)

Sander JD \& Joung JK 2014 CRISPR-Cas systems for editing, regulating and targeting genomes. Nature Biotechnology 32 347-355. (doi:10.1038/ nbt.2842)

Sher N, Yivgi-Ohana N \& Orly J 2007 Transcriptional regulation of the cholesterol side chain cleavage cytochrome P450 gene (CYP11A1) revisited: binding of GATA, cyclic adenosine $3^{\prime}, 5^{\prime}$-monophosphate response element-binding protein and activating protein (AP)-1 proteins to a distal novel cluster of cis-regulatory elements potentiates AP-2 and steroidogenic factor-1-dependent gene expression in the rodent placenta and ovary. Molecular Endocrinology 21 948-962. (doi:10.1210/me.20060226)

Siggers P, Smith L \& Greenfield A 2002 Sexually dimorphic expression of Gata-2 during mouse gonad development. Mechanisms of Development 111 159-162. (doi:10.1016/S0925-4773(01)00602-5)

Silverman E, Eimerl S \& Orly J 1999 CCAAT enhancer-binding protein beta and GATA-4 binding regions within the promoter of the steroidogenic acute regulatory protein (StAR) gene are required for transcription in rat ovarian cells. Journal of Biological Chemistry 274 17987-17996. (doi:10.1074/jbc.274.25.17987)

Silverman E, Yivgi-Ohana N, Sher N, Bell M, Eimerl S \& Orly J 2006 Transcriptional activation of the steroidogenic acute regulatory protein (StAR) gene: GATA-4 and CCAAT/enhancer-binding protein beta confer synergistic responsiveness in hormone-treated rat granulosa and HEK293 cell models. Molecular and Cellular Endocrinology 252 92-101. (doi:10.1016/j.mce.2006.03.008)

Smith CA, Roeszler KN, Ohnesorg T, Cummins DM, Farlie PG, Doran TJ \& Sinclair AH 2009 The avian Z-linked gene DMRT1 is required for male sex determination in the chicken. Nature 461 267-271. (doi:10.1038/ nature08298)

Sodhi CP, Li J \& Duncan SA 2006 Generation of mice harbouring a conditional loss-of-function allele of Gata6. BMC Developmental Biology 6 19. (doi:10.1186/1471-213X-6-19)

Stocco C, Kwintkiewicz J \& Cai Z 2007 Identification of regulatory elements in the Cyp19 proximal promoter in rat luteal cells. Journal of Molecular Endocrinology 39 211-221. (doi:10.1677/JME-07-0026)

Svensson EC, Tufts RL, Polk CE \& Leiden JM 1999 Molecular cloning of FOG-2: a modulator of transcription factor GATA-4 in cardiomyocytes. PNAS 96 956-961. (doi:10.1073/pnas.96.3.956)

Tevosian SG, Deconinck AE, Cantor AB, Rieff HI, Fujiwara Y, Corfas G \& Orkin SH 1999 FOG-2: a novel GATA-family cofactor related to multitype zinc-finger proteins Friend of GATA- 1 and U-shaped. PNAS 96 950-955. (doi:10.1073/pnas.96.3.950)

Tevosian SG, Deconinck AE, Tanaka M, Schinke M, Litovsky SH, Izumo S, Fujiwara Y \& Orkin SH 2000 FOG-2, a cofactor for GATA transcription factors, is essential for heart morphogenesis and development of coronary vessels from epicardium. Cell 101 729-739. (doi:10.1016/ S0092-8674(00)80885-5)

Tevosian SG, Albrecht KH, Crispino JD, Fujiwara Y, Eicher EM \& Orkin SH 2002 Gonadal differentiation, sex determination and normal Sry expression in mice require direct interaction between transcription partners GATA4 and FOG2. Development 129 4627-4634.

Thomas KR \& Capecchi MR 1987 Site-directed mutagenesis by gene targeting in mouse embryo-derived stem cells. Cell 51 503-512. (doi:10.1016/0092-8674(87)90646-5)

Thomas KR, Fogler KR \& Capecchi MR 1986 High frequency targeting of genes to specific sites in the mammalian genome. Cell 44 419-428. (doi:10.1016/0092-8674(86)90463-0)

Tohonen V, Frygelius J, Mohammadieh M, Kvist U, Pelliniemi LJ, O'Brien K, Nordqvist K \& Wedell A 2005 Normal sexual development and fertility in testatin knockout mice. Molecular and Cellular Biology 25 4892-4902. (doi:10.1128/MCB.25.12.4892-4902.2005)

Tremblay JJ \& Viger RS 1999 Transcription factor GATA-4 enhances Müllerian inhibiting substance gene transcription through a direct interaction with the nuclear receptor SF-1. Molecular Endocrinology 13 1388-1401.

Tremblay JJ \& Viger RS 2001 GATA factors differentially activate multiple gonadal promoters through conserved GATA regulatory elements. Endocrinology 142 977-986. 
Vidal VP, Chaboissier MC, de RD \& Schedl A 2001 Sox9 induces testis development in XX transgenic mice. Nature Genetics 28 216-217. (doi:10.1038/90046)

Viger RS, Mertineit C, Trasler JM \& Nemer M 1998 Transcription factor GATA-4 is expressed in a sexually dimorphic pattern during mouse gonadal development and is a potent activator of the Müllerian inhibiting substance promoter. Development 125 2665-2675.

Viger RS, Guittot SM, Anttonen M, Wilson DB \& Heikinheimo M 2008 Role of the GATA family of transcription factors in endocrine development, function, and disease. Molecular Endocrinology 22 781-798. (doi:10.1210/me.2007-0513)

Wagner EF, Stewart TA \& Mintz B 1981 The human $\beta$-globin gene and a functional viral thymidine kinase gene in developing mice. PNAS 78 5016-5020. (doi:10.1073/pnas.78.8.5016)

Wang H, Hu YC, Markoulaki S, Welstead GG, Cheng AW, Shivalila CS, Pyntikova T, Dadon DB, Voytas DF, Bogdanove AJ et al. 2013 TALENmediated editing of the mouse $\mathrm{Y}$ chromosome. Nature Biotechnology $\mathbf{3 1}$ 530-532. (doi:10.1038/nbt.2595)

Watanabe K, Clarke TR, Lane AH, Wang X \& Donahoe PK 2000 Endogenous expression of Müllerian inhibiting substance in early postnatal rat Sertoli cells requires multiple steroidogenic factor- 1 and GATA-4-binding sites. PNAS 97 1624-1629. (doi:10.1073/pnas.97.4.1624)

Waterston RH, Lindblad-Toh K, Birney E, Rogers J, Abril JF, Agarwal P, Agarwala R, Ainscough R, Alexandersson M, An P et al. 2002 Initial sequencing and comparative analysis of the mouse genome. Nature $\mathbf{4 2 0}$ 520-562. (doi:10.1038/nature01262)

Watt AJ, Battle MA, Li J \& Duncan SA 2004 GATA4 is essential for formation of the proepicardium and regulates cardiogenesis. PNAS 101 12573-12578. (doi:10.1073/pnas.0400752101)

Xuan S, Borok MJ, Decker KJ, Battle MA, Duncan SA, Hale MA, Macdonald RJ \& Sussel L 2012 Pancreas-specific deletion of mouse Gata4 and Gata6 causes pancreatic agenesis. Journal of Clinical Investigation 122 3516-3528. (doi:10.1172/JCI63352)
Yomogida K, Ohtani $H$, Harigae $H$, Ito $E$, Nishimune $Y$, Engel JD \& Yamamoto M 1994 Developmental stage- and spermatogenic cyclespecific expression of transcription factor GATA-1 in mouse Sertoli cells. Development 120 1759-1766.

Yoshimoto S, Ikeda N, Izutsu Y, Shiba T, Takamatsu N \& Ito M 2010 Opposite roles of DMRT1 and its W-linked paralogue, DM-W, in sexual dimorphism of Xenopus laevis: implications of a ZZ/ZW-type sexdetermining system. Development 137 2519-2526. (doi:10.1242/dev. 048751)

Zambrowicz BP, Imamoto A, Fiering S, Herzenberg LA, Kerr WG \& Soriano P 1997 Disruption of overlapping transcripts in the ROSAßgeo26 gene trap strain leads to widespread expression of $\beta$-galactosidase in mouse embryos and hematopoietic cells. PNAS 94 3789-3794. (doi:10.1073/pnas.94.8.3789)

Zaytouni T, Efimenko EE \& Tevosian SG 2011 GATA transcription factors in the developing reproductive system. Advances in Genetics 76 93-134. (doi:10.1016/B978-0-12-386481-9.00004-3)

Zeisberg EM, Ma Q, Juraszek AL, Moses K, Schwartz RJ, Izumo S \& Pu WT 2005 Morphogenesis of the right ventricle requires myocardial expression of Gata4. Journal of Clinical Investigation 115 1522-1531. (doi:10.1172/JCl23769)

Zhou B, Ma Q, Rajagopal S, Wu SM, Domian I, Rivera-Feliciano J, Jiang D, von Gise A, Ikeda S, Chien KR et al. 2008 Epicardial progenitors contribute to the cardiomyocyte lineage in the developing heart. Nature 454 109-113. (doi:10.1038/nature07060)

Received 14 February 2014

First decision 5 March 2014

Revised manuscript received 19 March 2014

Accepted 3 April 2014 